Galaxea, JCRS, 8: 25 - 37 (2006)

$J \Subset R S$

\title{
A new genus of paralcyoniid soft corals (Octocorallia, Alcyonacea, Paralcyoniidae) from the Indo-West Pacific
}

\author{
L.P. van Ofwegen ${ }^{1}$ and Y. Benayahu ${ }^{2}$
}

\author{
${ }^{1}$ Nationaal Natuurhistorisch Museum, P.O. Box 9517, 2300 RA Leiden, The \\ Netherlands (e-mail: ofwegen@naturalis.nnm.nl). \\ ${ }^{2}$ Department of Zoology, George S. Wise Faculty of Life Sciences, Tel Aviv \\ University, Ramat Aviv, 69978, Israel (e-mail: YehudaB@tauex.tau.ac.il).
}

\begin{abstract}
A new genus of paralcyoniid soft corals (Octocorallia: Paralcyoniidae) from the Indo-West Pacific is described and named Ceeceenus. The new genus is compared with the related genera Paralcyonium Milne Edwards, 1850 and Studeriotes Thomson \& Simpson, 1909. Four new species are described and included in the new genus. They were found in Thailand, Japan, Palau, Papua New Guinea and Tonga.
\end{abstract}

Key words: New genus. New species. Coelenterata. Cnidaria. Octocorallia. Alcyonacea. Paralcyoniidae. Indo-West Pacific.

\section{INTRODUCTION}

Recently a number of octocoral specimens have been collected in the Indo-West Pacific, which resemble the genus Paralcyonium, a genus only known to occur in the Mediterranean and East Atlantic, with only one representative, $P$. spinulosum (Delle Chiaje, 1822). This species has a remarkable colony growth form among octocorals, with a distinctive capsule-like base (pedicel) into which the trunk and branches can be withdrawn. Species of the Indo-Pacific genus Studeriotes Thomson \& Simpson, 1909, have a similar growth form but differ from $P$. spinulosum in having polyps with a supporting bundle, and lacking plateletlike sclerites. Moreover, colonies of Studeriotes are generally large in size while Paralcyonium colonies remain rather small. The present specimens are small (Figs. 1a-g), resemble $P$. spinulosum in colony growth form, have plateletlike sclerites, and lack a supporting bundle in the polyps, and therefore can be considered as being related to Paralcyonium. For a description of $P$. spinulosum we refer to Weinberg (1977, page 156$)$.

All material from the Indo-Pacific differs from Paralcyonium in having tentacular rods; Paralcyonium has no sclerites at all in the tentacles. As this character is normally only used to differentiate between species in soft corals, assigning the present material to Paralcyonium would at first seem justified. However, very few octocoral genera have been reported with a distribution of Mediterranean, Atlantic, and Indo-Pacific, and so far no specimens of these new taxa have been found from between the Atlantic and Thailand. This disjunct distribution pattern suggests the possibility we are dealing with a closely related new genus. Therefore, we decided to compare not only colony form and sclerites, but also the ultrastructure of the sclerites and molecular data.

We compared the ultrastructure of the sclerites of a specimen of $P$. spinulosum from Naples, Italy (RMNH Coel. 2987) (Fig. 2) with that of the material from Thailand. The two show a noticeably different ultrastructure, but are essentially built of similar lattice; i.e., in both the crystals flare towards the sclerite surface. It is noteworthy that in all material there seems to 

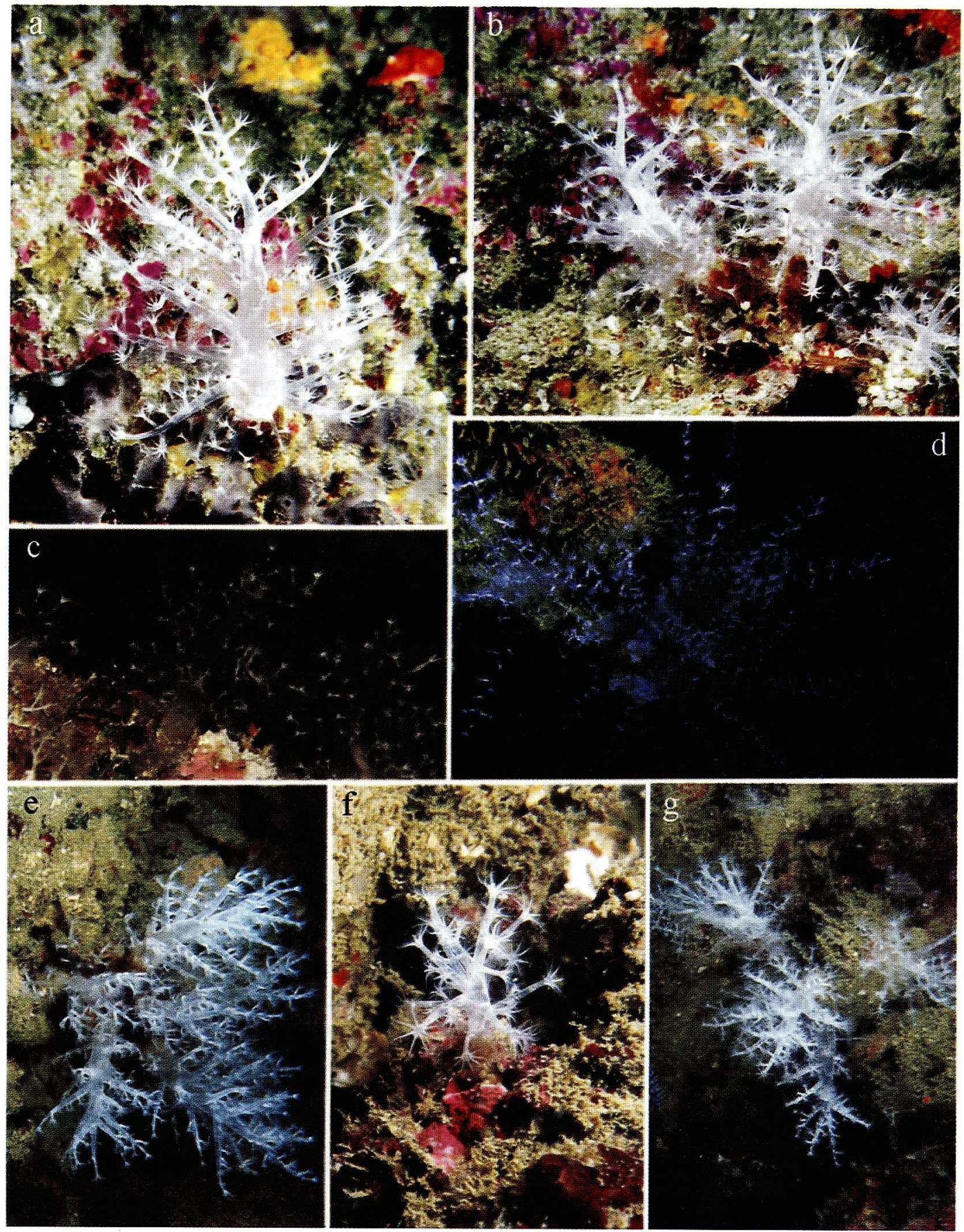

Fig. 1. Live colonies; a-b, Ceeceenus quadrus spec. nov.; c-d, C. torus spec. nov., c, from Palau, d, from Papua New Guinea; e-g, C. levis spec. nov.

be a correlation between sclerite size and crystal shape. $P$. spinulosum has slightly larger sclerites and the larger spindles of the Indo-Pacific material (Fig. 3g) have similar ultrastructure as the medium sized sclerites of $P$. spinulosum (Fig. 2e).

Dr. Catherine S. McFadden (Harvey Mudd College, Claremont, USA) kindly sequenced two mitochondrial genes, msh1 and ND2, for two specimens from Thailand, and compared the sequences with those of Studeriotes spec. and $P$. spinulosum. According to her they group closest to Paralcyonium in the tree, but they are quite distinct and lie intermediate between Paralcyonium and Studeriotes.

As the observed sclerite differences were rather small, and the molecular data were only based on 


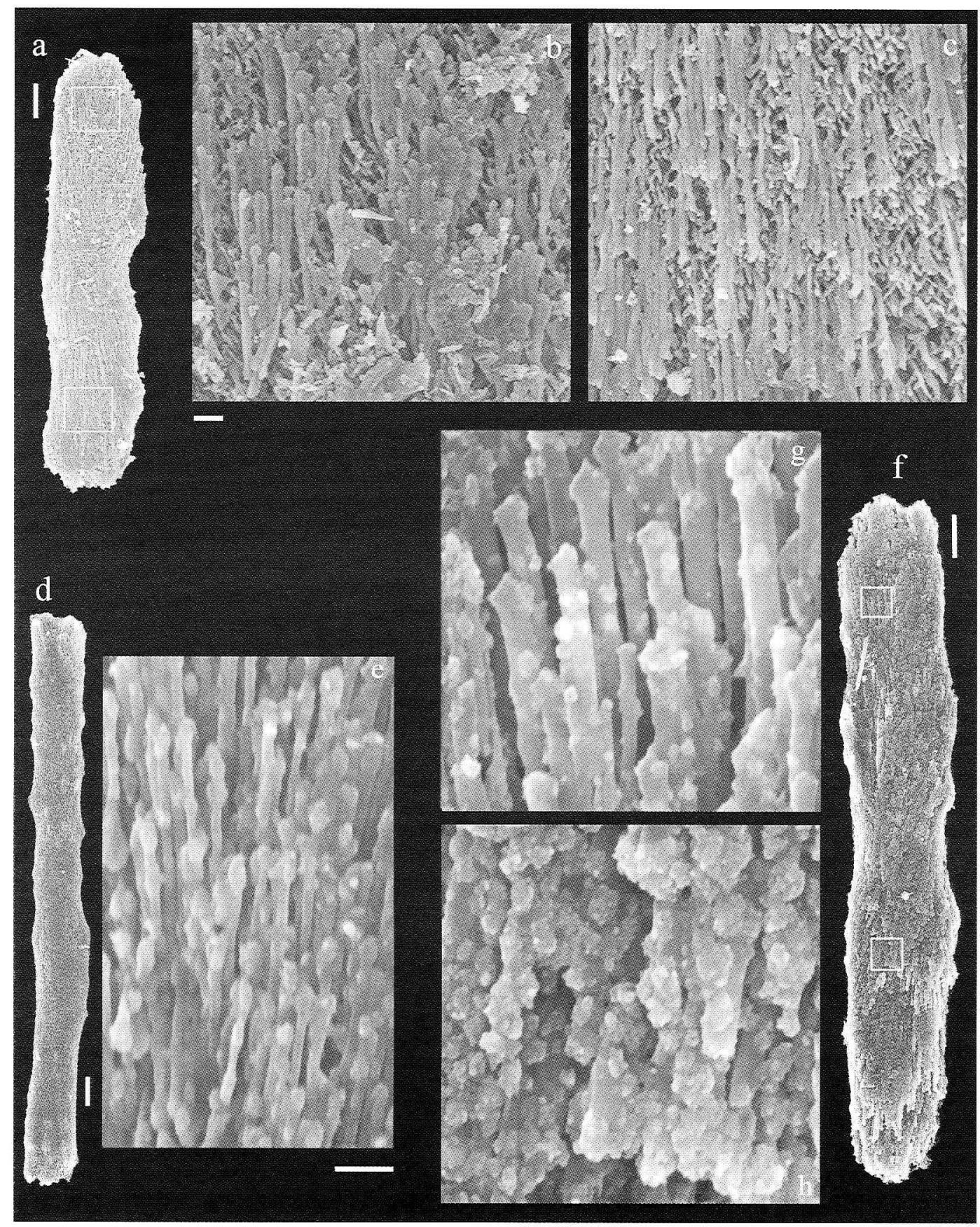

Fig. 2. Paralcyonium spinulosum (Delle Chiaje, 1822), RMNH Coel. 2987; three platelets (a, d, f) with ultrastructure $\left(\mathrm{b}^{-c}, \mathrm{e}, \mathrm{g}-\mathrm{h}\right)$. Scale of platelets $0.01 \mathrm{~mm}$, scales of ultrastructure $0.001 \mathrm{~mm}$.

two specimens, Ofwegen et al. (2004) presented the above findings during the $10^{\text {th }}$ International Coral Reef Symposium, Okinawa, Japan, on a poster entitled "The genus Paralcyonium (Octocorallia: Paralcyoniidae) in the Indo-West Pacific", presenting four new species of Paralcyonium.

During this conference Pat Colin (Coral Reef Research Foundation, Palau) informed us that he had seen similar colonies to those examined in the current study on Palau and offered to collect some. In addition, after the conference Gustav Paulay (Florida Museum of Natural History, Gainesville, Florida, USA) collected more material from Okinawa.

Using the new material from Palau we once more examined the ultrastructure of the sclerites (Fig. 3); the observed structure was identical to that of the Thai material. 


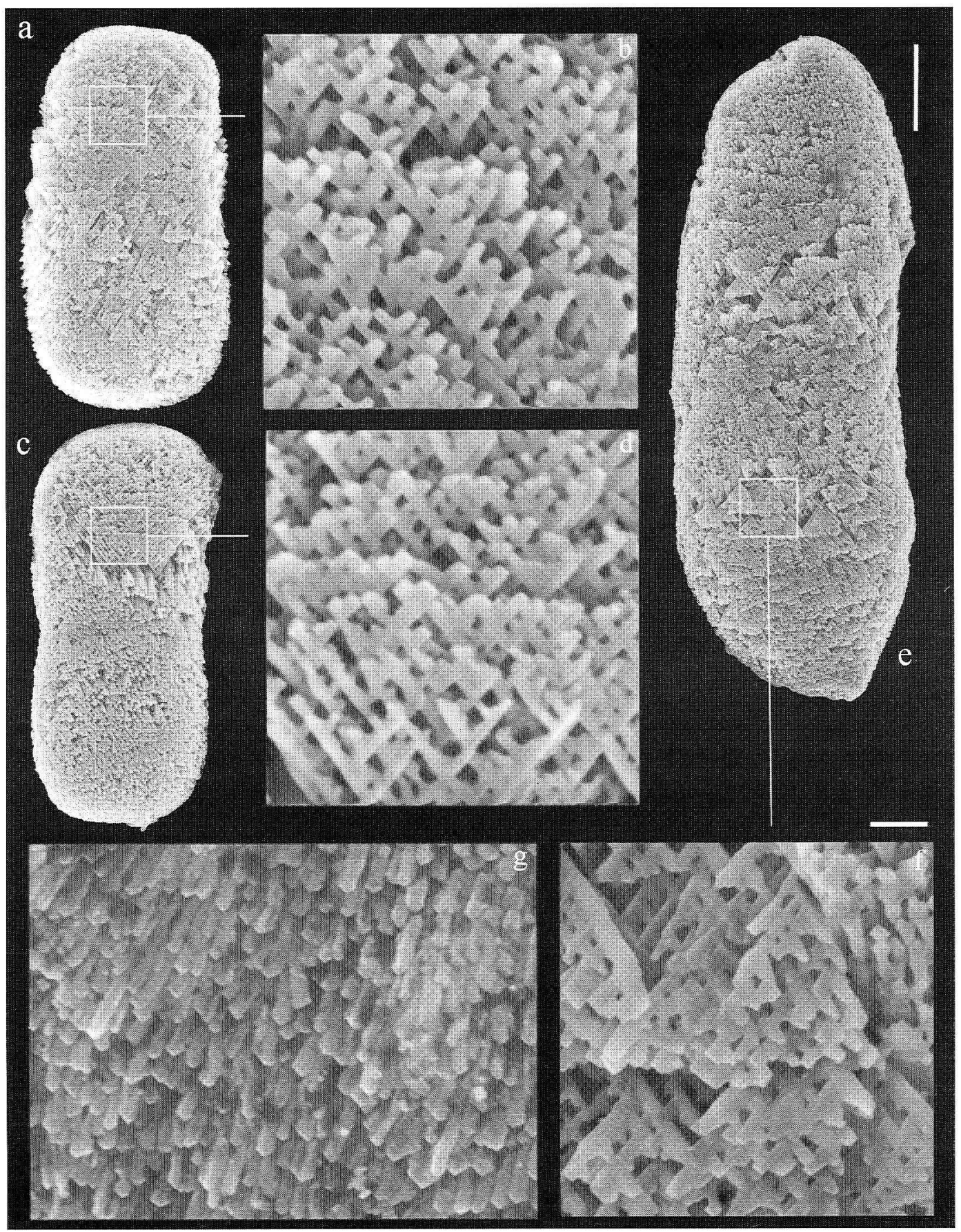

Fig. 3. Ceeceenus torus spec. nov., paratype RMNH Coel. 33679; three platelets (a, c, e) with ultrastructure $(\mathrm{b}, \mathrm{d}, \mathrm{f})$ and pedicel spindle ultrastructure $(\mathrm{g})$. Scale of platelets $0.01 \mathrm{~mm}$, scale of ultrastructure $0.001 \mathrm{~mm}$.

This recent collected material also allowed Dr. $\mathrm{McF}$ adden to sequence the Palau and Okinawan material using the msh1 gene. All three species involved proved to have identical sequences. To this Dr. McFadden added "msh1 is relatively invariant among species within most of the genera in this clade (Paralcyoniidae/ Nephtheidae), so the relatively large distance between the new paralcyoniids and $P$. spinulosum suggests a new genus" (pers. comm.).

Additionally, Wirshing et al. (2005), dealing with a molecular study of the octocoral family Plexauridae stated: "In several instances, genera containing Atlantic and Pacific species were recovered as monophyletic (Muricea spp., Bebryce spp.). However, in at least three cases (Echinomuricea 
spp., Thesea spp., Villogorgia spp.), placement of Atlantic and Pacific species in the same genus may reflect convergence of sclerite morphology".

In light of these new molecular data, constant difference in sclerite ultrastructure, different tentacular armature, and disjunct distribution, we decided to describe a new genus for the IndoPacific material, rather than assigning it to Paralcyonium. The new genus and four new species are described and depicted below. A key to the species of the new genus and $P$. spinulosum is presented.

\section{MATERIALS AND METHODS}

For the technical terms used in the descriptions we refer to Bayer et al. (1983). We only measured the polyp width, as the length was often difficult to ascertain due to variable degree of polyp contraction.

Abbreviations used: CRRF $=$ Coral Reef Research Foundation, Palau; RMNH = National Museum of Natural History (NNM), formerly Rijksmuseum van Natuurlijke Historie, Leiden, The Netherlands; UF = Florida Museum of Natural History, Gainesville, Florida, USA; ZMTAU = Zoological Museum, Tel Aviv University, Israel.

\section{Ceeceenus gen. nov.}

\section{Type species}

Ceeceenus levis spec. nov., by original designation.

\section{Diagnosis}

Paralcyoniid with colonies formed by groups of polyps, connected to each other by short stolons. Axial polyp with daughter polyps widely spaced forming a loosely branched polyparium, which is retractile within a common pedicel. Trunk, branches, and tentacles of polyps have platelets. Polyps with points composed of spindles, and an indistinct collaret. Pedicel with spindles provided with simple to slightly complex tubercles. No zooxanthellae in the tissue.

\section{Etymology}

A combination of letters, gender masculine.

\section{Differentiation}

The genus differs from Studeriotes Thomson \& Simpson, 1909, by forming smaller colonies, having platelets, and lacking a supporting bundle in the polyps. It differs from Paralcyonium Milne
Edwards, 1850, by having platelets in the tentacles and a different sclerite ultrastructure.

The spindles of the pedicel showed hardly any differences in shape or ornamentation between the different species, the length measured for these spindles of the pedicel also should be considered of limited diagnostic value. For comparison with $P$. spinulosum (see Weinberg, 1977, plate 17) the ornamentation of pedicel spindles of $C$. levis spec. nov. is presented in Fig. $4 \mathrm{~g}-\mathrm{h}$.

\section{Remarks}

Thomson \& Dean (1931: 185) reported Paralcyonium spinulosum (as P. elegans) from the Ceram Sea, Indonesia. They described a specimen kept on formalin, probably a small specimen of Studeriotes.

\section{Key to the species of Paralcyonium and Ceeceenus}

1. Tentacles without sclerites...... P. spinulosum (Delle Chiaje, 1822).

- Tentacles with platelets......... 2

2. Platelets with both entire and ragged outline C. pannosus spec. nov.

-. All platelets with entire outline 3

3. Anthocodial spindles rather thick, also filling up the space between points.

Many platelets are squarish in shape

C. quadrus spec. nov.

-. Anthocodial spindles are slender. Platelets mostly elongate

4

4. Anthocodial spindles mostly with protuberances. Below points varying numbers of platelets

\section{C. torus spec nov.}

-. Anthocodial spindles mostly without ornamentation. Many platelets are present below points.

\section{C. levis spec. nov.}

\section{Ceeceenus levis spec. nov.}

\section{Material}

(Figs. 1e-g, 4a, e-h, 5, 9)

RMNH Coel. 33672, holotype and 5 microscope slides; station number Phu.19, S Thailand, Phiphi Islands, W Ko Phiphi Le, S of Maya Bay, 740’30"N 9845'42”E, 6 April 2003, coll. B.W. Hoeksema, SCUBA diving, 20-24 m; 


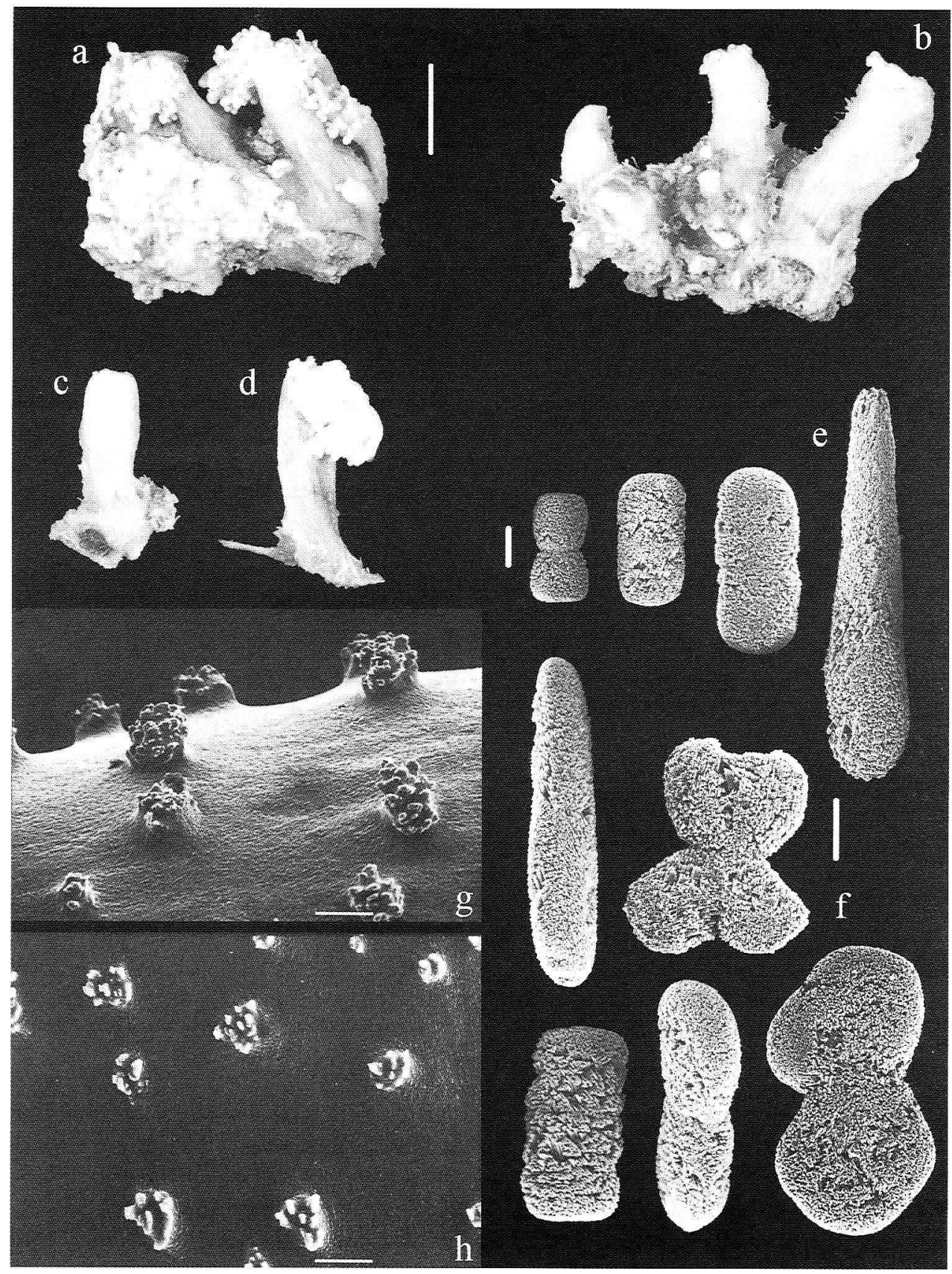

Fig. 4. a, holotype Ceeceenus levis spec. nov.; b, holotype C. quadrus spec. nov.; c, holotype C. pannosus spec. nov.; d, holotype $C$. torus spec. nov.; e-h, C. levis spec. nov., e-f, platelets, g-h, ornamentation of pedicel spindles. Scale at a $10 \mathrm{~mm}$, applies to a-d, scales at e-h $0.01 \mathrm{~mm}$.

RMNH Coel. 33673, around 40 paratypes, same data as holotype.

\section{Description}

The holotype is a group of six polyp aggregates on a piece of rock (Fig. 4a). The largest of these aggregates is about two $\mathrm{cm}$ high, including expanded trunk, and its pedicel is about $0.50 \mathrm{~cm}$ wide. The Axial polyps are up to $1.30 \mathrm{~mm}$ wide, the smallest daughter polyps only $0.25 \mathrm{~mm}$ wide.

Tentacles have platelets that are up to 0.06 mm long (Fig. 5b). Anthocodial spindles mostly without ornamentation (Fig. 5c), up to about 0.35 $\mathrm{mm}$ long, arranged in eight points, with often one or two lying horizontally forming a kind of collaret (Fig. 5a). Platelets also occur in between the point spindles, directly below the 
points, and in the branches and trunk. They are similar in shape and size to those of the tentacles (Fig. 5d), and are most abundant in the branches, becoming less common in the trunk.

The pedicel has long spindles, up to about 4 $\mathrm{mm}$ long, with sparse tubercular sculpture.

\section{Etymology}

The Latin "levis", smooth, in reference to the anthocodial spindles without ornamentation.

\section{Remarks}

The species resembles C. quadrus in that the space between two points is also more or less completely filled with sclerites, but differs in having more elongated platelets and more slender point spindles. C. levis has platelets similar to those of $C$. torus, but differs in having $\mathrm{nu}^{-}$ merous anthocodial spindles without ornamentation.

Living colonies in their natural habitat are shown in Fig. 1e-g.

\section{Distribution}

The species is only known from the type $10^{-}$ cality (Fig. 9).

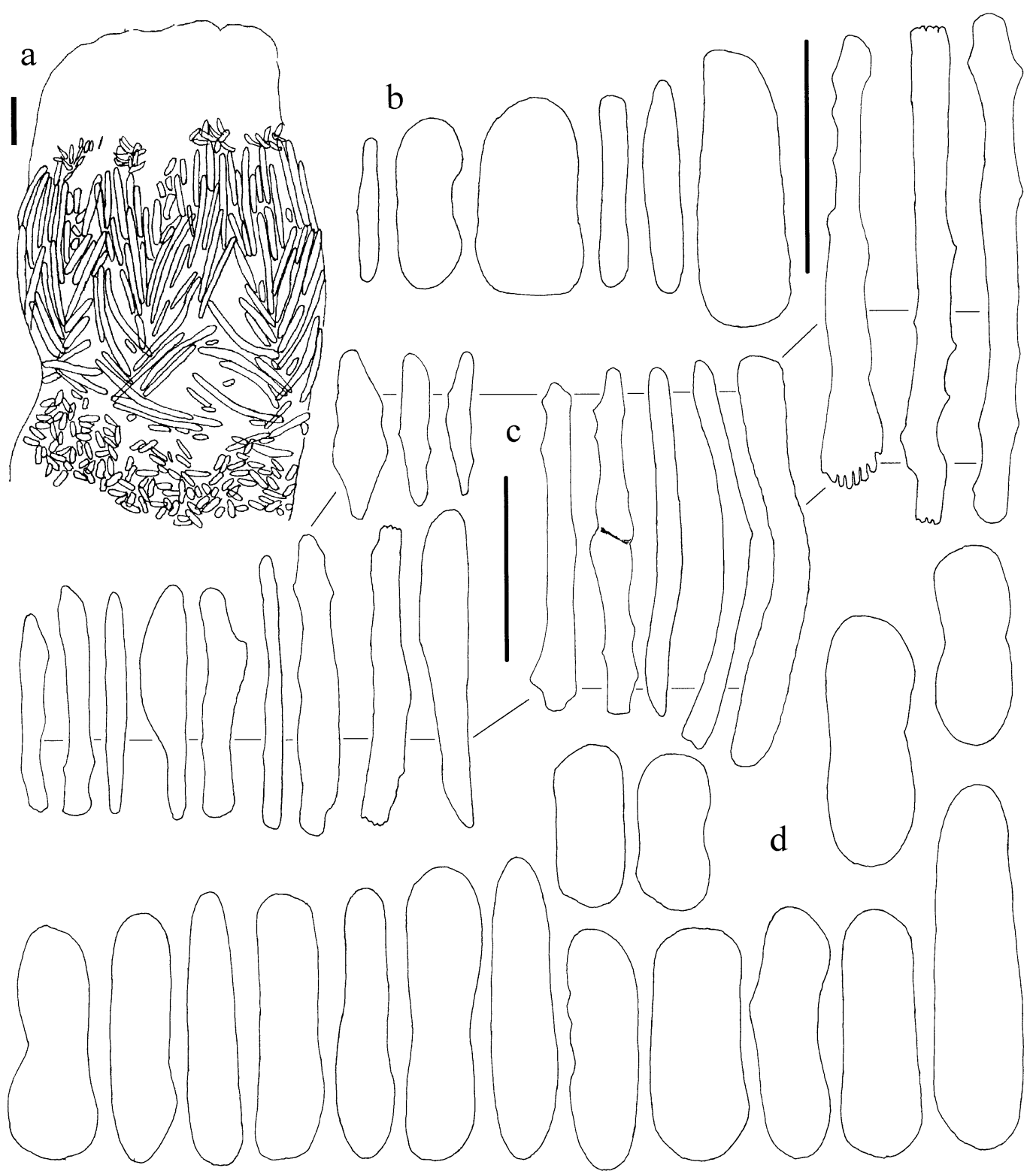

Fig. 5. Ceeceenus levis; holotype RMNH Coel. 33672; a, lateral view of polyp armature; b-d, sclerites; b, tentacles; c, points; d, trunk. Scales $0.10 \mathrm{~mm}$. 


\section{Ceeceenus pannosus spec. nov.}

(Figs. 4c, 6, 9)

\section{Material}

UF 899, holotype Tonga, Haapai Group, north end of Haano Island, forereef, in crevice, $33 \mathrm{~m}$, $19^{\circ} 38.15^{\prime} \mathrm{S} 174^{\circ} 17.933^{\prime} \mathrm{W}$, coll. G. Paulay, 11 September 1996; RMNH Coel. 33674, 2 microscope slides of holotype.

\section{Description}

The holotype is about two $\mathrm{cm}$ high and 0.70 mm wide (Fig. 4c). It is cylindrical in shape and the trunk with all anthocodiae is withdrawn into the pedicel. The Axial polyps are up to about $1 \mathrm{~mm}$ wide, the smallest daughter polyp only $0.50 \mathrm{~mm}$ wide.

Tentacles have platelets up to $0.05 \mathrm{~mm}$ long, with an entire or ragged edge. Most tentacles are withdrawn within the polyp body, in only one polyp were platelets clearly visible, and these five were depicted (Fig. 6b). Anthocodiae have sparsely tuberculated spindles (Fig. 6c), up to about 0.60 $\mathrm{mm}$ long, arranged in eight points, with one or two often lying horizontally, forming a kind of collaret (Fig. 6a). In between these points some

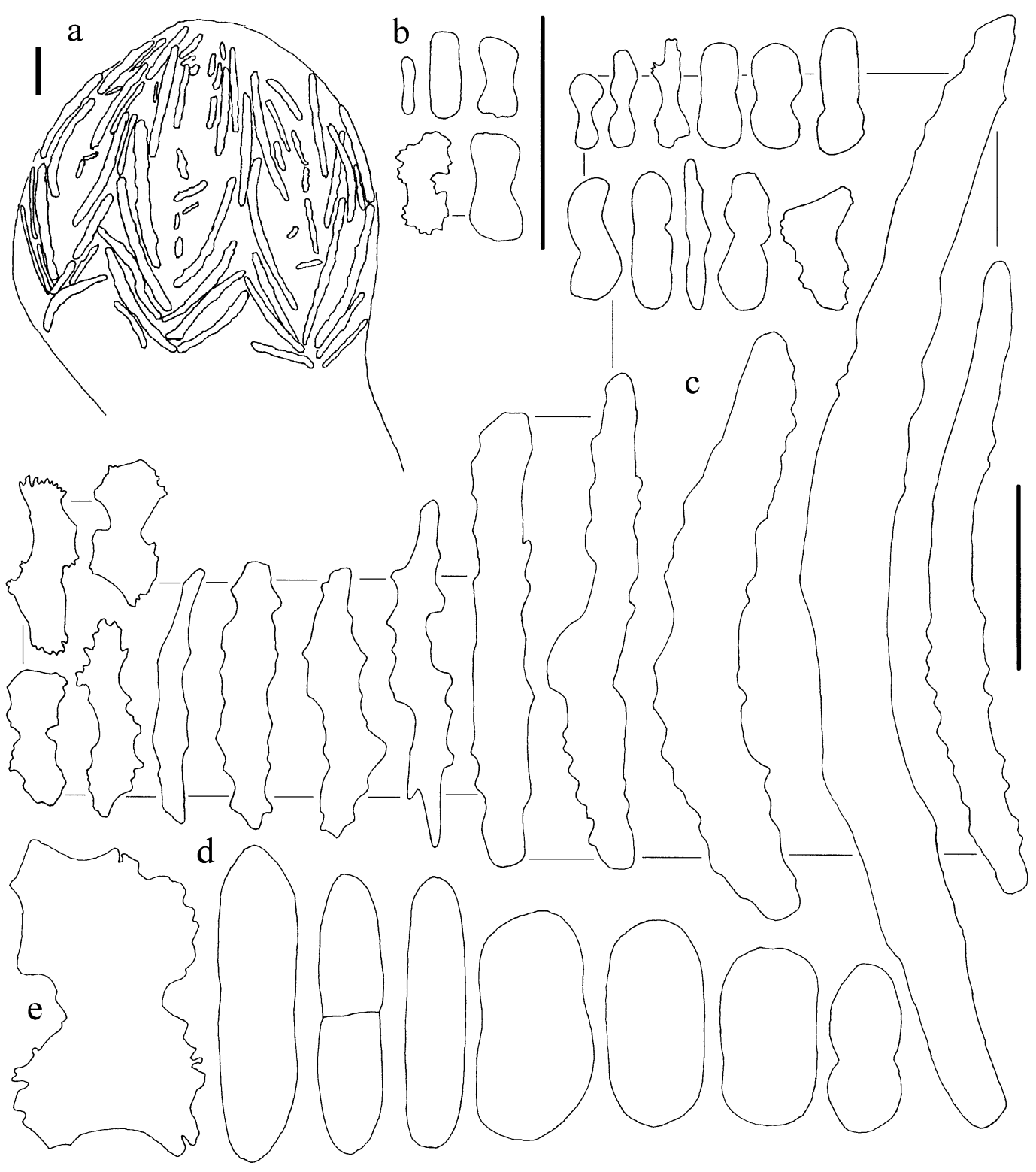

Fig. 6. Ceeceenus pannosus; holotype UF 899; a, lateral view of polyp armature; b-e, sclerites; b, tentacles; c, points; d, trunk; e, probably from trunk. Scales $0.10 \mathrm{~mm}$. 
smaller spindles and platelets are also present, the latter similar in shape to the tentacular ones (Fig. 6c, e). Below the points platelets are completely lacking, but in the trunk they are present, slightly longer than those of the tentacles (Fig. 6d).

Pedicel has long spindles, up to about $3 \mathrm{~mm}$ in length, with sparse tubercular sculpture.

\section{Etymology}

The Latin "pannosus", ragged, in reference to the ragged edge of several of the platelets.

\section{Remarks}

The species differs from the other three Ceeceenus species in having platelets with a ragged edge and much longer anthocodial spindles.

\section{Distribution}

The species is only known from the type lo- $^{-}$ cality (Fig. 9).

\section{Ceeceenus quadrus spec. nov.}

\section{Material}

(Figs. 1a-b, 4b, 7, 9)

ZMTAU Co 31079, holotype, Japan, Okinawa, Akajima Island, Fukakanese $32 \mathrm{~m}, 26^{\circ} 10.242^{\prime} \mathrm{N}$ $127^{\circ} 13.831^{\prime} \mathrm{E}$, coll. Y. Benayahu; RMNH Coel. 33675, 3 microscope slides of holotype; ZMTAU Co 31082, paratype, same data as holotype; RMNH Coel. 33676, 2 microscope slides of paratype; UF 2858, 5 paratypes, Japan, Okinawa, Ie Island, Kanan-zaki, NW end of island, outer reef slope, $10-15 \mathrm{~m}, 26^{\circ} 44.35^{\prime} \mathrm{N} 127^{\circ} 48.605^{\prime} \mathrm{E}$, coll. G. Paulay \& S. Kinjo, 8 July 2004; RMNH Coel. 33677, 1 microscope slide of UF 2858.

\section{Description}

The holotype is a group of three polyp aggregates on a piece of rock (Fig. 4b). The largest of these aggregates is about two $\mathrm{cm}$ high, and its pedicel is up to $0.8 \mathrm{~cm}$ wide. In all three aggregates most of the anthocodiae and the complete trunk are withdrawn into the pedicel. The Axial polyps are up to about $1.40 \mathrm{~mm}$ wide, the smallest daughter polyp only $0.60 \mathrm{~mm}$ wide.

Tentacles have platelets up to $0.07 \mathrm{~mm}$ long (Fig. 7b). Anthocodial spindles mostly without ornamentation (Fig. 7c), up to about $0.35 \mathrm{~mm}$ long, arranged in eight points, with one or two often lying horizontally forming a kind of collaret (Fig. 7a). The space between the points is also completely filled with spindles, but these are somewhat shorter than the point spindles.
Directly below the points and in the branches and trunk platelets similar to those of the tentacles occur, but these are slightly longer and wider (Fig. 7d). The number of platelets below the points varies, sometimes only a few are present; towards the trunk the number increases.

Pedicel has long spindles, up to about $6 \mathrm{~mm}$ long, with sparse tubercular sculpture.

\section{Etymology}

The Latin "quadrus", square, in reference to the square shaped platelets found in the branches and trunk.

\section{Remarks}

The species resembles C. levis, but differs in having somewhat wider anthocodial spindles and somewhat more square platelets.

The species feels more rigid than the other Ceeceenus species, probably because it has larger pedicel spindles.

The ZMTAU Co 31082 paratype is a single aggregate of polyps of similar size, but with completely withdrawn trunk and anthocodiae. The UF 2858 paratypes are also single colonies but have expanded trunk and anthocodiae. They show several polyps with sclerite arrangement more like that of $C$. torus or $C$. levis, i.e. with points clearly separated from each other and with some platelets in between adjacent points. Also the anthocodial spindles show more ornamentation than usual for C. guadrus, resembling that of $C$. torus. However, the UF 2858 material shows the same square platelets and the same variation in number of platelets below the points as the holotype and paratype ZMTAU Co 31082 .

Living colonies are shown in Fig. 1a-b.

\section{Distribution}

The species is only known from two localities near Okinawa, Japan (Fig. 9).

\section{Ceeceenus torus spec. nov.}

\section{Material}

$$
\text { (Figs. 1c-d, 3, 4d, 8, 9) }
$$

UF 900, five colonies, one of which was chosen as the holotype (Fig. 4d), Papua New Guinea, Milne Bay Province, Alotau, patch reef, under overhang on small ledge, about $15 \mathrm{~m}$, coll. J. Starmer, 8 June 1998; RMNH Coel. 33678, 3 microscope slides of the holotype; RMNH Coel. 33679, Palau, West channel, about $30 \mathrm{~m}$, coll. 
Pat Colin, 8 February 2005, four paratypes and two microscope slides.

\section{Description}

The holotype has a pedicel about $2 \mathrm{~cm}$ high and $0.70 \mathrm{~cm}$ wide. The trunk and anthocodiae are expanded but are hanging down from the pedicel (Fig. 4d).
Tentacles have platelets up to $0.06 \mathrm{~mm}$ long (Fig. 8b). Anthocodiae have sparsely tuberculated spindles (Fig. 8c), up to about $0.35 \mathrm{~mm}$ long, arranged in eight points, and often one or two lying horizontally forming a kind of collaret (Fig. 8a). In between these points some smaller spindles and platelets are also present, the latter similar in shape to the tentacular ones.

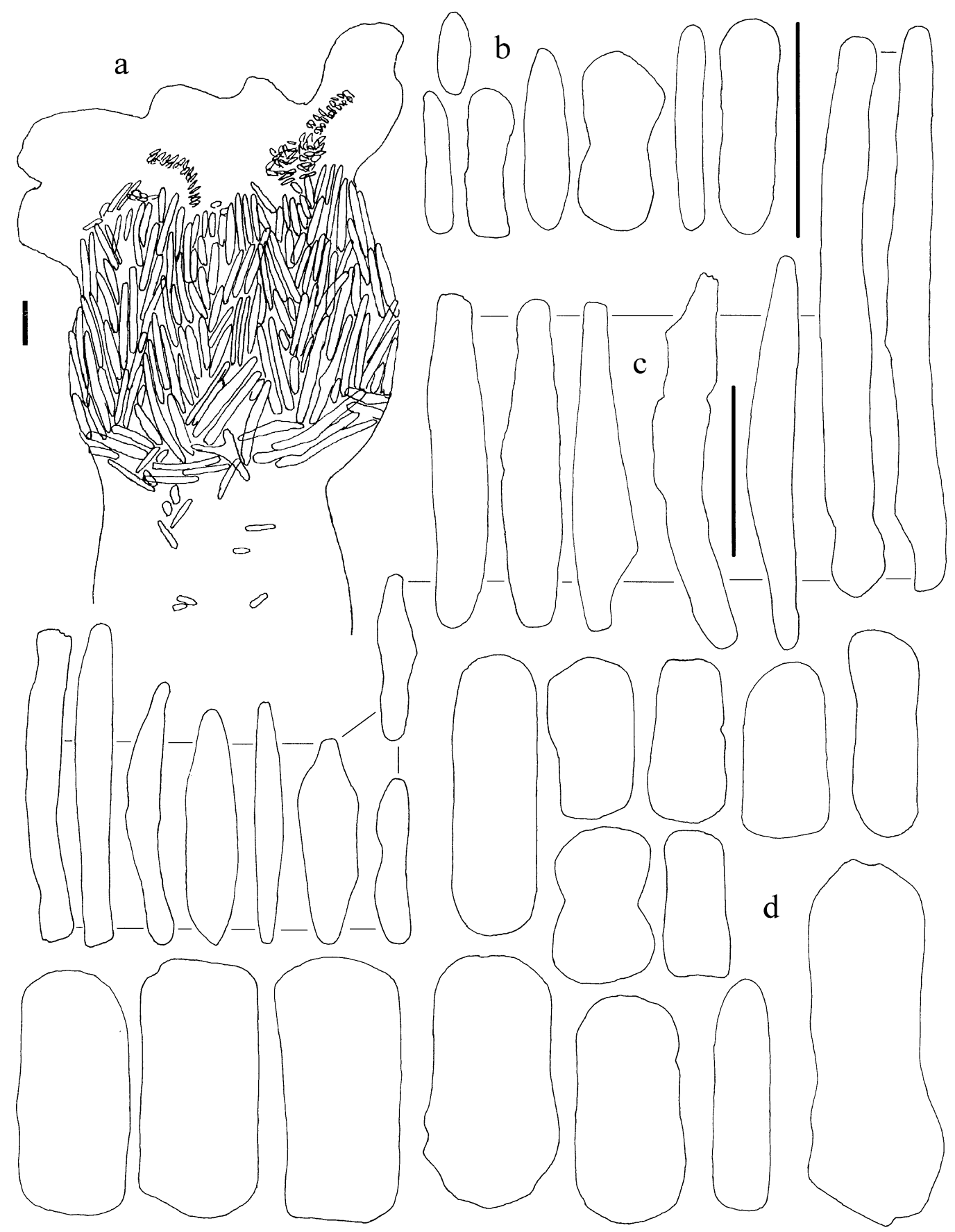

Fig. 7. Ceeceenus quadrus, holotype ZMTAU Co 31079 ; a, lateral view of polyp armature; b-d, sclerites; b, tentacles; c, points; d, trunk. Scales $0.10 \mathrm{~mm}$. 


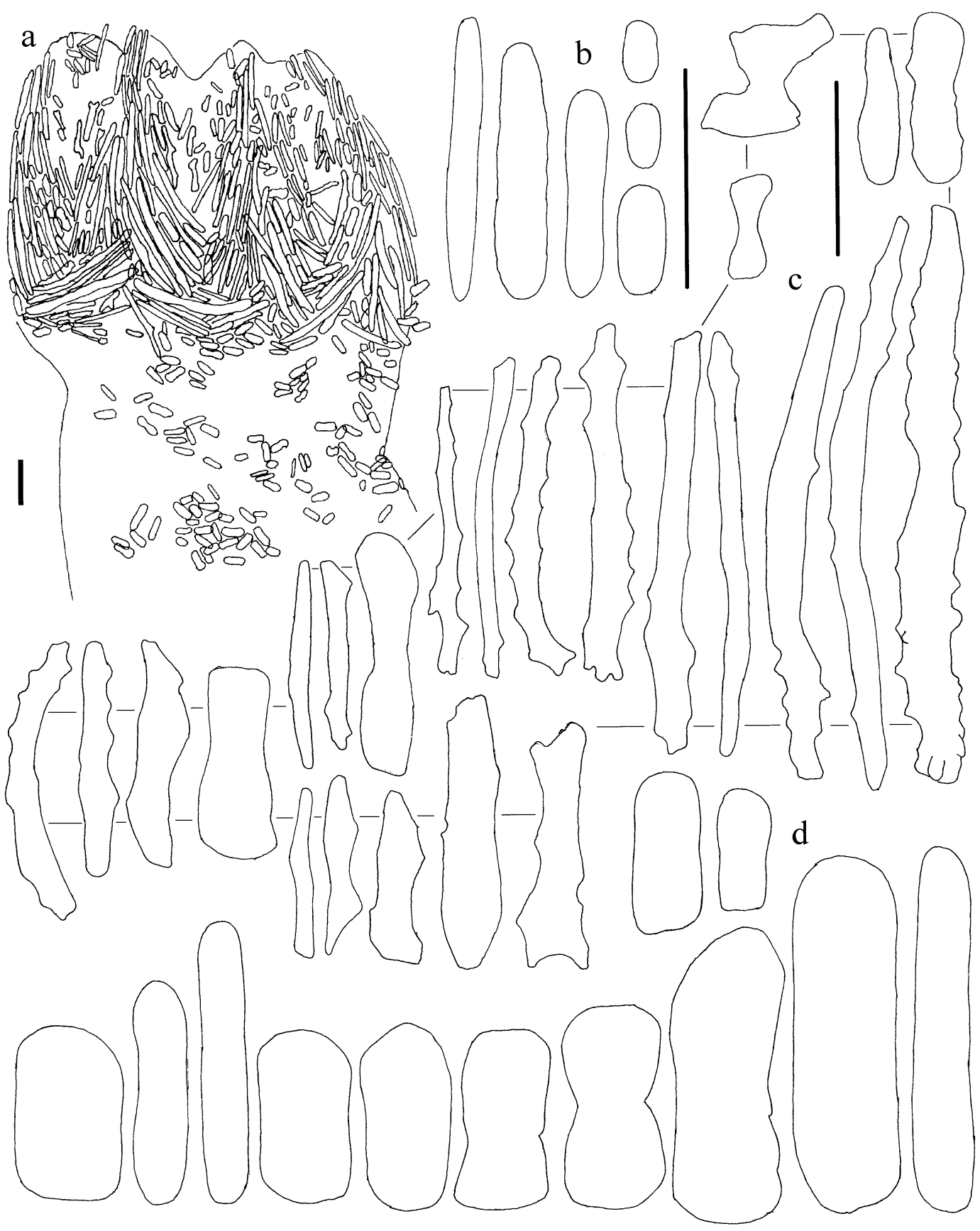

Fig. 8. Ceeceenus torus; holotype UF 900; a, lateral view of polyp armature; b-d, sclerites; b, tentacles; c, points; d, trunk. Scales $0.10 \mathrm{~mm}$.

Directly below the points and in the branches and trunk, platelets similar to those of the tentacles occur, but they are slightly longer (Fig. 8d). Pedicel has long spindles, up to about $5 \mathrm{~mm}$ long, with sparse tubercular sculpture.

\section{Etymology}

The Latin "torus", protuberance, in reference to the anthocodial spindles with protuberances, a noun in apposition.

\section{Remarks}

The species resembles $C$. levis but differs in having point spindles that are more tuberculate and fewer sclerites between adjacent points.

Living colonies are shown in Fig. 1c-d. 


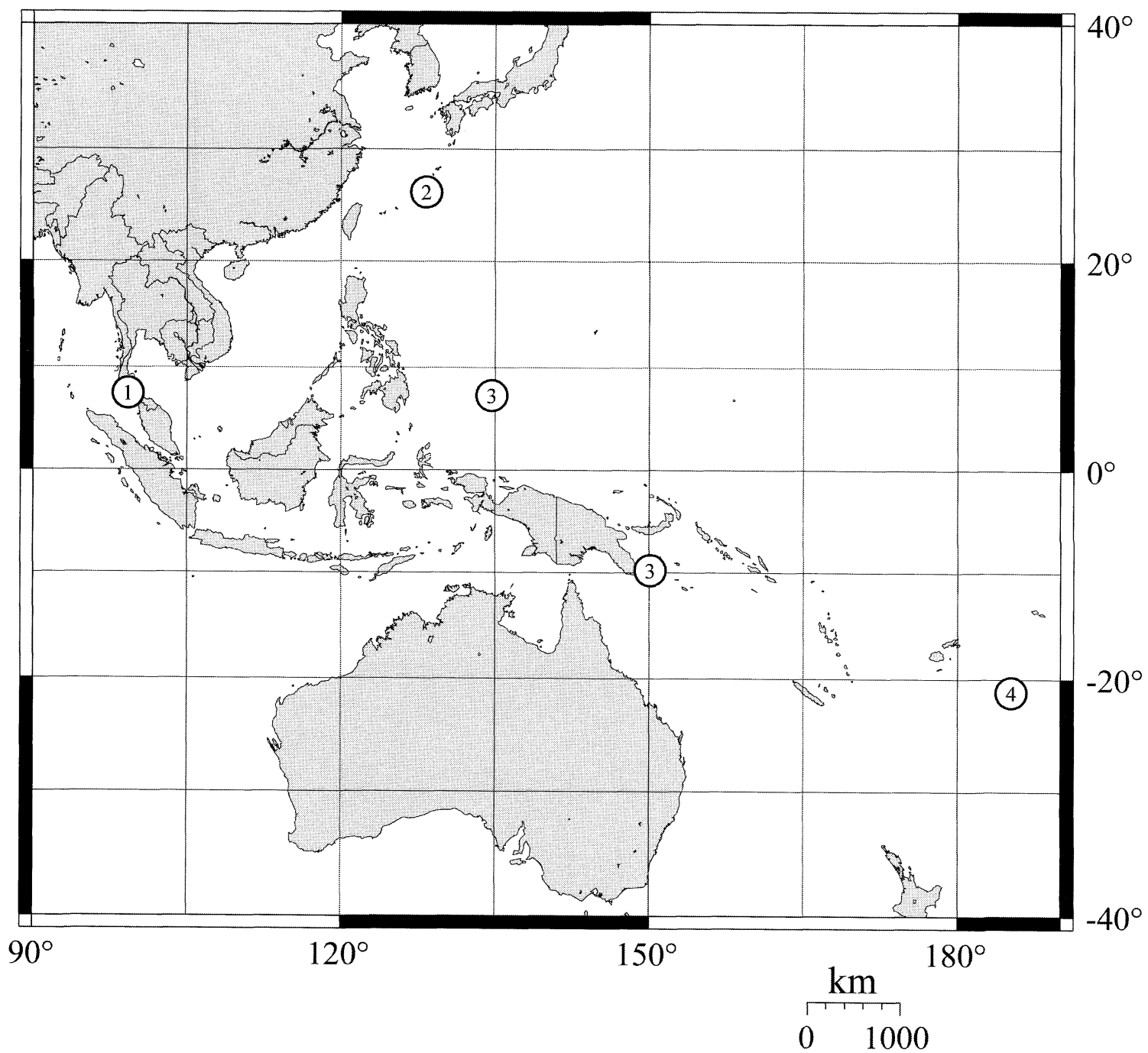

Fig. 9. Distribution of Indo-Pacific Ceeceenus species. $1=$ C. levis spec. nov.; $2=$ C. quadrus spec. nov.; 3 =C. torus spec. nov.; $4=$ C. pannosus spec. nov.

\section{Distribution}

The species is known from the type locality Papua New Guinea, and Palau (Fig. 9).

\section{ACKNOWLEDGEMENTS}

We like to thank John Starmer and Gustav Paulay (UF), Pat Colin (CRRF), and Bert Hoeksema (RMNH) for collecting specimens, and entrusting the material and photographs to us for study. Collection of the specimens of $C$. torus was made possible through a contract from the U.S. National Cancer Institute to the CRRF. We thank Dr. Junichi Tanaka for assistance during the field work in Okinawa and for contributing the underwater photographs of $C$. quadrus. Mr. Jeroen Goud (RMNH) is acknowledged for help with several of the SEM photographs, Mr. Chiel Slierings for curatorial assistance, and Dr. Catherine S. McFadden (Harvey Mudd College, Claremont, USA) is thanked for sharing her molecular data with us.

\section{REFERENCES}

Bayer FM, Grasshoff M, Verseveldt J (1983) Illustrated trilingual glossary of morphological and anatomical terms applied to Octocorallia. Leiden: 1-75.

Delle Chiaje S (1822) Memoire sulla storia e notonomia degli animali senza vertebre del regno di Napoli. Atlas: Pls. I-IV, I-LXIX. 
Società Tipografica, Napoli.

Milne Edwards H, Haime J (1850) Monograph of the British fossil corals. Part 1: Introduction; corals from Tertiary and Cretaceous formations. London, Palaentographical Society: ilxxxv+1-71, pls. 1-11.

Ofwegen LP van, Starmer J, Benayahu Y (2004) Poster at $10^{\text {th }}$ International Coral Reef Symposium (Okinawa) entitled: The genus Paralcyonium (Octocorallia: Paralcyoniidae) in the Indo-West Pacific.

Thomson JA, Dean LM (1931) The Alcyonacea of the Siboga Expedition with an addendum to the Gorgonacea. Siboga-Exped. Monogr. 13d: 1-227, pls. 1-28.

Thomson JA, Simpson JJ (1909) An account of the alcyonarians collected by the Royal Indian Marine Survey Ship Investigator in the Indian Ocean; with a report on the species of Dendronephthya by W.D. Henderson. II. The alcyonarians of the littoral area. Calcutta, The Indian Museum: i-xviii+1-319, pls 1-9.

Weinberg, S (1977) Revision of the common Octocorallia of the Mediterranean circalittoral II. Alcyonacea. Beaufortia 25 (326): 131-166, pls. 1-18.

Wirshing HH, Messing CG, Douady CJ, Reed J, Stanhope MJ, Shivji MS (2005) Molecular evidence for multiple lineages in the gorgonian family Plexauridae (Anthozoa: Octocorallia). Marine Biology 147: 497-508.

(Received: 30 Nov. 2005/Accepted: 11 April. 2006) 